\title{
O Moderno antes do Modernismo: paradoxos da pintura brasileira no nascimento da República
}

Ana Paula Cavalcanti Simioni

Lúcia K. Stumpf

RESUMO: O presente artigo discute a especificidade da pintura brasileira produzida durante a Primeira República (1889-1930), a qual não pode ser compreendida nem como uma continuidade harmônica em relação à tradição herdada pelo Império e nem mediante o rótulo de "pré-moderna". A partir da interpretação de duas telas, Os descobridores, de Belmiro de Almeida, e Fundação da cidade de São Paulo, de Antônio Parreiras, pretende-se examinar os sentidos políticos e culturais particulares que as obras engendram, os quais emanam dos momentos e condições específicos de sua produção, bem como da relação crítica que possuem para com a tradição acadêmica no país. PALAVRAS-CHAVE: Pintura de história, Academismo, Primeira República, Belmiro de Almeida, Antônio Parreiras.

ABSTRACT: The present article discusses the specificity of the Brazilian painting produced during the First Republic (1889-1930), which cannot be understood as a harmonic continuity in relation to the tradition inherited by the Empire, nor be labeled as "pre-modern". Through the interpretation of two paintings, Os descobridores, by Belmiro de Almeida, and Fundação da cidade de São Paulo, by Antônio Parreiras, we set out to examine the specific political and cultural meanings that these works generate, which emanate from a certain moment and condition of their production, as well as from their critical relationship towards the academic tradition of the country.

KEYWORDS: History painting, Academicism, First Republic, Belmiro de Almeida, Antônio Parreiras. 
“A República não produziu uma estética própria”. A frase, categórica, encontra-se no clássico livro A formação das almas, ${ }^{1}$ obra fundamental para os interessados na relação entre cultura e política na Primeira República. O autor, José Murilo de Carvalho, afirma que todos os esforços ocorridos no país, por imitarem os modelos de república franceses, o que significa também a iconografia em circulação na III República francesa, teriam redundado em um grande fracasso.

Essa visão negativa diante da arte produzida no Brasil entre 1890 e 1922 é bastante generalizada. Vista como europeizada, desenraizada, elitista, cosmopolita etc., a pintura desse momento tende a ser condenada por não estar vinculada a uma plataforma nacionalista, a qual se tornou obrigatória a partir da ascensão dos modernistas em meados dos anos 1920. Nem mesmo aqueles artistas considerados pelos modernistas como os melhores desse momento, como Almeida Jr., escapam das armadilhas analíticas. Vistos como antecessores do moderno, tais artistas são compreendidos pela rubrica de "pré-modernos", termo em si problemático, como bem analisa Jorge Coli.

Afinal:

O antefixo pré, por exemplo, possui armadilhas por vezes definitivas. Porque raramente designa apenas uma anterioridade: ele faz com que um conjunto de obras e de acontecimentos deixe de adquirir sentido em si próprio para definir-se através do futuro, ele faz esquecer que os critérios culturais presentes à criação existiam numa coerência específica. ${ }^{2}$

E continua:

É legítimo buscar nas obras e nos momentos artísticos o seu passado: os criadores dos quais eles derivam servem-lhe de raízes. É, ao contrário, enganoso construir-lhes um futuro, e adivinhar neles aquilo que não podiam prever. ${ }^{3}$

1. Carvalho, José Murilo de. A formação das almas. São Paulo: Companhia das Letras, 2009.

2. COLI, Jorge. O Brasil redescoberto.Paço Imperial, set./nov. 1999. Minc/Iphan, p. 130.

3. Id., p. 130. 
Ora associados a uma permanência indesejável dos legados do Império em tempos de República, logo como artistas tradicionais, incapazes de acompanhar os rumos da história,ora, como no caso dos "pré-modernos", compreendidos como artistas cuja capacidade de responder aos apelos do presente é incompleta e inconclusa, essa geração não chega a possuir sequer um nome, um rótulo capaz de absorvê-la, representá-la. Se os artistas do Império são "acadêmicos", termo limitado, pois não suporta as clivagens e multiplicidade de estilos presentes na instituição, e se a geração de 1920/30 será a dos "modernos", os artistas da Primeira República não possuem um termo capaz de agrupá-los. Por vezes utiliza-se a evocação francesa de artistas pompiers para designá-los, termo bastante problemático, como bem mostrou Jacques Thuilier, ${ }^{4}$ uma vez que não se trata de uma categoria fundada em qualidades estilísticas, mas sim proveniente de uma gíria que circulava nos ateliês franceses na segunda metade do século $\mathrm{xx}$.

Acreditamos que tais impasses da nomenclatura expõem a grande dificuldade em se compreender tal produção e geração de artistas em seus próprios termos, ou seja, analisá-las como projetos artísticos vinculados a demandas específicas de um momento histórico e cultural particular. Mas antes de tentarmos entender que momento é esse, vale retornarmos às críticas de Carvalho.

\section{O FRACASSO DO IMAGINÁRIO REPUBLICANO}

Segundo José Murilo de Carvalho, a República teria falhado na capacidade de promover símbolos nacionais integradores, o que se deixa ver, especialmente, na dificuldade de se impor uma representação heroica nesse período. É interessante notar que a transformação na Academia Francesa promovida pela Revolução de 1789, levada internamente a cabo por Jacques Louis David, havia tornado o herói uma representação central. Como ressalta Friedlander:

O herói [...] não era apenas alguém que realizava grandes feitos ou proezas físicas e cuja força muscular e beleza física causavam admiração. Ele era, antes de mais nada, alguém

4. THUILIER, Jacques. Peut-on parler d'une peinture "pompier"? Paris: Presses Universitaires de France, fev. 1984 . 
[...] cujo nobre corpo revisita uma alma resplandecente de virtude e cujas realizações poderiam servir de exemplo como um ideal a ser atingido. ${ }^{5}$

Segundo Carvalho, heróis são símbolos poderosos de ideias, aspirações que os tornam instrumentos capazes de atingir a mente e o coração dos cidadãos a serviço da legitimação de regimes políticos. Todos os regimes políticos buscam promovê-los. Sem fugir à regra, a Primeira República brasileira realizou esforços neste sentido, no entanto as clivagens entre os grupos militares, que tentaram associar a fundação do Regime ao Marechal Deodoro da Fonseca, e os grupos civis, de orientação positivista, que tentaram fazer de Benjamim Constant o idealizador do movimento, expuseram a dificuldade de encontrar uma imagem consensual. Os heróis elevados neste momento personificavam frações, grupos em disputa, e dessa forma eram aceitos por uns e recusados por outros, sem levar a cabo, portanto, a tarefa de legitimação do regime pela população. Paradoxalmente, como bem demonstra o autor, é nesse momento que emerge a representação de Tiradentes como um herói nacional, o que não deixa de evidenciar ainda mais as dificuldades enfrentadas pela República, visto que se tratava de um líder recrutado em um contexto histórico distanciado, e cuja aceitação coletiva advinha justamente das associações então construídas entre seu martírio e a saga cristã; com isso, enalteciam-se justamente aqueles aspectos imaginários que o distanciavam de crenças e práticas civis, laicas e republicanas.

\section{PARADOXOS DA PINTURA BRASILEIRA NO NASCIMENTO DA REPÚBLICA}

Apesar da inegável importância do livro, da perspicácia dos argumentos mobilizados e da inegável pertinência da crítica estabelecida pelo autor à República brasileira enquanto regime cujas promessas não se cumprem, é preciso relativizar algumas das afirmações veiculadas em $A$ formação das almas acerca da produção dos artistas plásticos durante a Primeira República.

Em primeiro lugar, existe um problema que diz respeito ao recorte espacial abarcado pelas imagens analisadas. As interpretações desenvolvidas por José Murilo de Carvalho incidem exclusivamente sobre a produção artística realizada no Rio de

5. Friedlander, Walter. De David a Delacroix. São Paulo: Cosac Naify, 2001, p. 19. 
Janeiro, capital da República nascente. É, portanto, a partir da compreensão do que se processa no centro que o autor formula uma teoria geral sobre o que ocorre no país. No entanto, uma das marcas fundamentais desse período é a descentralização política e também cultural. Um breve olhar para as capitais dos recém-instituídos estados federativos revela um panorama cultural muito mais rico, agitado por diversas encomendas públicas levadas a cabo pelos governantes locais no sentido de promover a glorificação de feitos, fatos e heróis atrelados a um discurso regional. ${ }^{6}$

O pintor Antônio Parreiras (1860-1937) foi um dos artistas mais acionados pelas elites locais nesse momento, respondendo a encomendas de estados como o Pará, Rio de Janeiro, São Paulo, Rio Grande do Sul, Paraíba, Rio Grande do Norte. Além dele, artistas como Teodoro Braga e Rodolfo Amoedo, entre outros, respondem a tais apelos. Acreditamos que, sem olhar para esta produção, a análise desenvolvida por Carvalho fica incompleta e redunda em incompreensões.

Isso porque tal deslocamento político se traduz em outro deslocamento, agora de modalidades artísticas. Carvalho procura exclusivamente nas telas de cavalete a produção do período. No entanto, as mais importantes encomendas públicas do período tendem a se materializar em projetos decorativos, ou seja, ensejam não telas, mas sim obras murais, ou ainda pinturas destinadas a cobrirem grandes superfícies. A produção mais rica dessa época deve, portanto, ser buscada não nas pinturas de cavalete apresentadas nos salões, mas nas obras que compõem tais projetos decorativos encomendados

6. Cf. GUTFReInd, Ieda. A construção de uma identidade: a historiografia sul-rio-grandense de 1925 a 1975. 1989. Tese (Doutorado). São Paulo:FflCh-usP; fERreira, Antônio Celso. A epopeia bandeirante: letrados, instituições, invenção histórica (1870-1940). São Paulo: Ed. Unesp, 2002; MELLo, Evaldo Cabral de. Rubro veio: o imaginário da restauração pernambucana. Rio de Janeiro: Topbooks, 1997; GUimARÃES, Eduardo Henrique de Lima. Religião, pátria e liberdade: a historiografia do IAGP entre 1862 e 1876.1996. Dissertação (Mestrado em História). Recife:Depto. de História da Universidade Federal de Pernambuco; RaImundo, Silvia Lopes. A invenção do mito bandeirante: tradição e pensamento regionalista na historiografia paulista das décadas de 1920-1930.2001. Dissertação (Mestrado em Geografia). São Paulo:Depto. de Geografia da fflch da usP; ferretti, Danilo. Callari, Cláudia Regina. "Os institutos históricos: do patronato de d. Pedro I à construção do Tiradentes". Revista Brasileira de História. São Paulo, v.21, n.4O, pp.59-83, 2001; sCHwARCZ, Lilia Moritz. O espetáculo das raças. São Paulo: Companhia das Letras, 1993, pp. 99-140; Os guardiões da nossa história oficial: os institutos históricos e geográficos brasileiros. São Paulo: IDESP, 1989. Série História das Ciências Sociais, n. 9. Albuquerque JR., Durval Muniz de. A invenção do Nordeste e outras artes. Recife: Joaquim Nabuco/ Massangana; São Paulo: Cortez, 2001. 
pelos estados e municípios, destinados a serem as vitrines do novo regime, como bem compreendeu o pesquisador Arthur Valle, cujo doutorado ${ }^{7}$ versou sobre os projetos decorativos do Rio de Janeiro, como o do Supremo Tribunal Federal, ou ainda o Palácio Tiradentes. Análises desse tipo necessitam ser feitas para o escopo do país, se quisermos compreender os discursos visuais propagados nesse momento.

Tendo em vista tais considerações, é possível retornarmos à questão da figuração do herói. Será mesmo que a República não teria sido capaz de engendrar novas representações heroicas? Analisando as pinturas de história produzidas no país entre finais do século xIx e inícios do xx, Maraliz Christo ${ }^{8}$ aponta um movimento geral de enfraquecimento do herói na iconografia brasileira, o qual ecoava uma tendência equânime produzida na Europa, notadamente em Paris, que ainda nesse período era o centro de produção a ditar modelos para a arte local. Sua análise está ancorada em três obras, Tiradentes esquartejado(1893) de Pedro Américo, Os Bandeirantes(1889) de Henrique Bernardelli e Os descobridores(189o) de Belmiro de Almeida, nas quais o heroísmo se encontra atenuado, ironizado ou simplesmente impossibilitado.

Entretanto, quando se observa o conjunto de telas e esculturas hoje salvaguardadas pelo Museu Paulista da Universidade de São Paulo, talvez seja possível interpretar de maneira diversa tal questão. A maior parte dessas obras resulta de encomendas realizadas por Afonso d'Escragnolle Taunay, diretor da instituição entre os anos de 1917 e 1939, com vistas às comemorações do centenário da Independência, em 1922. Como bem demonstrou Paulo Garcez Marins, ${ }^{9}$ nas obras encomendadas entre 1917 e 1922, a figura do bandeirante emerge bastante heroicizada. Para tanto, sob recomendações do diretor, os pintores e escultores contratados recuperam uma iconografia específica, a denominada "pose real" presente desde os retratos barrocos, com vistas a dignificar a imagem desses heróis que atravessaram o século $\mathrm{xx}$

7. valle, Arthur. A pintura da Escola Nacional de Belas Artes na $1^{a}$ República (189o-1930). Tese de doutoramento apresentada à EBA da Universidade Federal do Rio de Janeiro, 2007. Sobre isso ver também: Valle, Arthur. "Pintura decorativa na $1^{a}$ República, formas e funções". Revista19ぬ 20 . Rio de Janeiro, v. II, n. 4 , out. 2007.

8. Christo, Maraliz. Pintura, história e heróis: Pedro Américo é Tiradentes esquartejado. Tese de doutoramento apresentada ao IFCH da Universidade Estadual de Campinas, 2005. Sobre isso ver também: CHRISTO, Maraliz. "Bandeirantes ao chão". Revista Estudos Históricos. Rio de Janeiro, v. II, n. 30, 2002.

9. MARINS, P. C. G."Nas matas com pose de reis: a representação de bandeirantes e a tradição da retratística monárquica europeia".Revista do Instituto de Estudos Brasileiros, v. 44, pp. 77-104, 2007.

116 • SIMIONI, Ana Paula C. \& STUMPF, Lúcia. O Moderno antes do Modernismo... 
no imaginário popular, nos livros didáticos, como os responsáveis pelo atual mapa do país, ícones da "bravura" dos paulistas.

Tal caso ilumina a necessidade de se entender a produção artística realizada durante a Primeira República a partir de um prisma metodológico específico, que seja sensível ao fato de que essas imagens mobilizam uma tradição artística da qual são tributárias, mas que se atualiza historicamente, que se renova quando confrontada às demandas políticas efetuadas por elites regionais em busca de afirmação em escala nacional.

\section{MODERNO ANTES DO MODERNISMO}

A fim de contribuir para o debate sobre a especificidade da produção artística na Primeira República brasileira, abordaremos duas obras realizadas no período: as telas Os descobridores, de Belmiro de Almeida, e Fundaçãoda cidade de São Paulo, de Antônio Parreiras. Trata-se de duas pinturas que por sua temática e dimensão podem ser classificadas como pinturas de história ligadas a eventos de notória importância para a historiografia nacional, bem como para a regional. Nesse sentido, configuram um diálogo com a tradição artística oitocentista. No entanto, o modo como tais eventos são figurados, a forma com que a heroicidade é tratada em cada uma delas, demonstra um distanciamento crítico com respeito à tradição, contrapondo-se ao caráter fortemente idealizado dos "fatos" históricos tal como eram elaborados nas telas produzidas ao longo do Segundo Reinado. Por essas continuidades e contrastes, as obras podem ser tomadas como indicativas do caráter particular da produção do período, sinalizadoras do que se entendia então por "modernidade".

Belmiro de Almeida, pintor brasileiro originário de Minas Gerais, destacara-se já no Salão de 1884 diante do olhar atento de GonzagaDuque, principal crítico de arte do período. Comentando a exposição geral de belas-artes daquele ano, apontou-o como uma das mais vigorosas forças de renovação da pintura nacional, em especial por sua tela Arrufos, dedicada a uma rusga conjugal. O crítico afirma: "Belmiro é o primeiro, pois, a romper com os precedentes, é o inovador; é o que compreendendo por uma maneira mais clara a arte do seu tempo, interpreta um assunto novo". ${ }^{\circ}$

10. DUQUe, Gonzaga. A arte brasileira. Campinas: Mercado das Letras, 1995, p. 212 (Grifo nosso). 
A renovação temática efetuada pelo pintor, vista por Gonzaga Duque como o verdadeiro caminho que a arte nacional deveria seguir, tinha, certamente, inspirações no além-mar. Como muitos dos seus colegas de geração, Belmiro realizara uma parte de sua formação na França, mais precisamente na Académie Julian, em Paris, entre 1896 e 1899. É preciso notar que uma das características da produção desse período é o desejo de incorporar os modelos artísticos franceses. Grande parte dos pintores e escultores nacionais desse momento passou uma temporada em Paris, com vistas a aprimorar seus conhecimentos na École de Beaux-Arts ou na Academie Julian, que recebeu mais de cem patrícios entre seus membros entre 188 o e 1922. Por vezes, esses artistas de orientação acadêmica são percebidos como incapazes de incorporar as "novidades" artísticas de seu tempo, que estariam disponíveis em Paris. Novidade, neste caso, aparece como sinônimo de vanguarda impressionista. Tal perspectiva estabeleceu-se como um primado analítico ao longo do século $\mathrm{xx}$, resultado da ascensão de determinados grupos artísticos que, ao vencerem as rivalidades travadas com seus pares, impuseram como legítima a sua visão de mundo e a sua concepção de arte. ${ }^{11}$ Mas tal orientação precisa ser revista. Ao invés de utilizarmos modelos a-históricos sobre o que seria classificável como "arte moderna", parece-nos mais apropriado entender, por meio de casos específicos, qual o sentido das obras em seu próprio contexto, isto é, qual o sentido que o termo "Moderno" possuía para esses artistas ou como ele está presente nas próprias obras. ${ }^{12}$

A tela Os descobridores, realizada em 1899 possivelmente com vistas à comemoração do IV Centenário do Descobrimento do Brasil, estabelece um diálogo perceptível com a tela Le Pauvre Pêcheur, de Puvis de Chavannes. Formalmente há grande afinidade entre as figuras representadas. Em ambas, ressalta-se uma conotação acentuadamente popular, sendo a tela francesa dedicada a um pobre pescador, acompanhado de sua esposa e filho, e a do brasileiro a dois homens maltrapilhos, sujos e desolados diante

11. Cf. Bourdieu, Pierre. O poder simbólico. Rio de Janeiro: Bertrand Brasil, 1992.

12. A esse respeito consultar: CosTA, Laura Malosetti. Los primeros modernos: arte y sociedad en Buenos Aires a fines del siglo XIX. Buenos Aires: Fondo de Cultura Económica de Argentina, 2001; simioni, Ana Paula Cavalcanti. "A viagem a Paris de artistas brasileiros no final do século xIx". Tempo Social. Revista de Sociologia da usP, v. 17, n.1, São Paulo, 2005; DAZZI, Camila.Pôr em prática a Reforma da Antiga Academia: a concepção e a implementação da reforma que instituiu a Escola Nacional de Belas Artes em 1890. 2011. Tese de Doutorado apresentada ao Programa de Pós-Graduação em Artes Visuais (História e Crítica da Arte), Escola de Belas Artes da Universidade Federal do Rio de Janeiro, 2011.

118 - SIMIONI, Ana Paula C. \& STUMPF, Lúcia. O Moderno antes do Modernismo... 


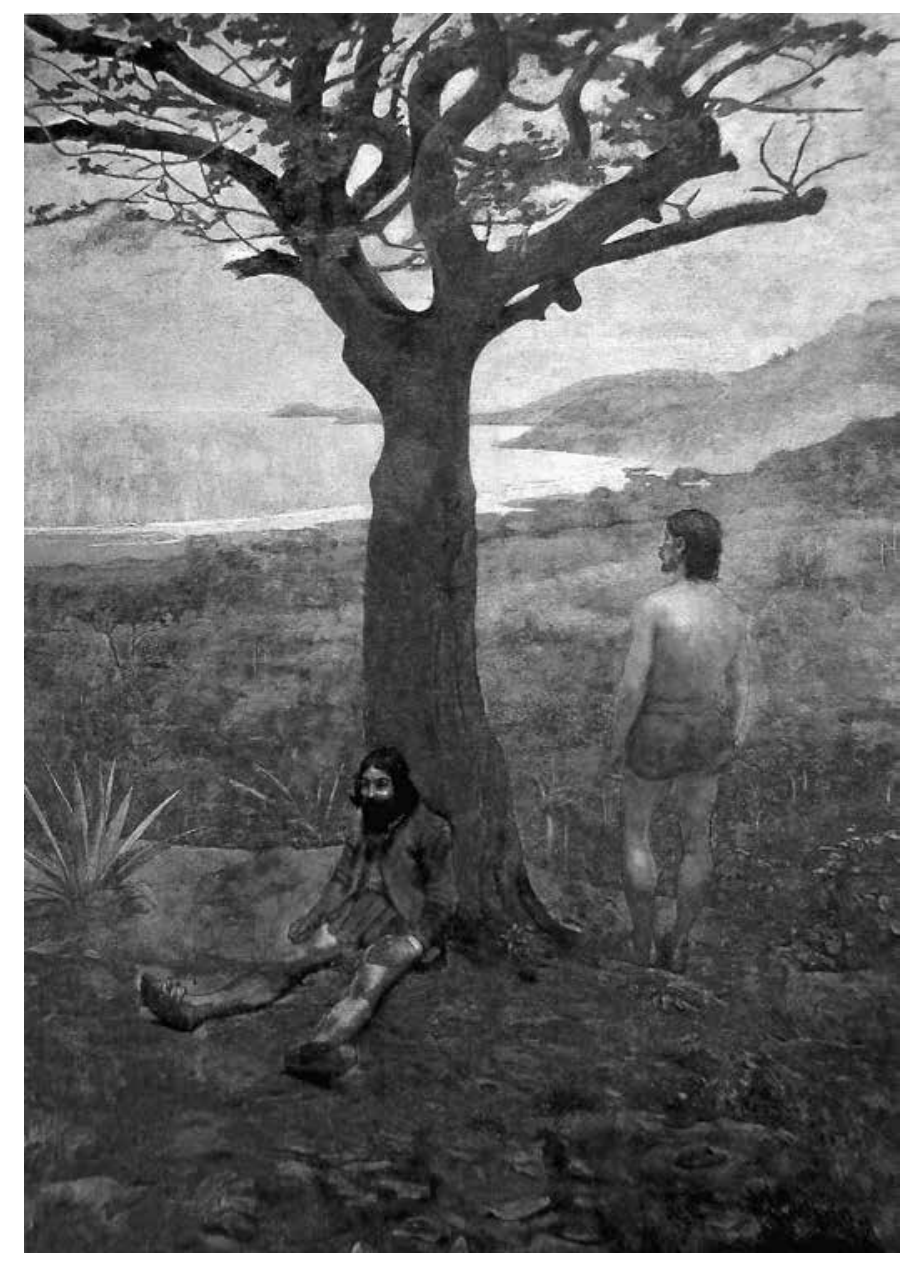

Belmiro de Almeida. Os Descobridores, 1899.

Óleo sobre tela, $260 \times 200 \mathrm{~cm}$. Rio de Janeiro, Museu Histórico do Itamaraty.

da nova terra em que parece terem acabado de atracar. O cromatismo também é muito similar, com opção por tons terrosos e por certo embranquecimento espesso da paleta. Mesmo na composição há pontos de convergência: em ambas o horizonte é cortado por uma linha, quase abstrata, que caracteriza o mar, e há uma presença comum de grandes espaços vazios na tela, que também revelam uma propensão para a geometrização e para a escala das obras murais.

Pierre Puvis de Chavannes (1824-1898) foi considerado por Pierre Vaisse como 


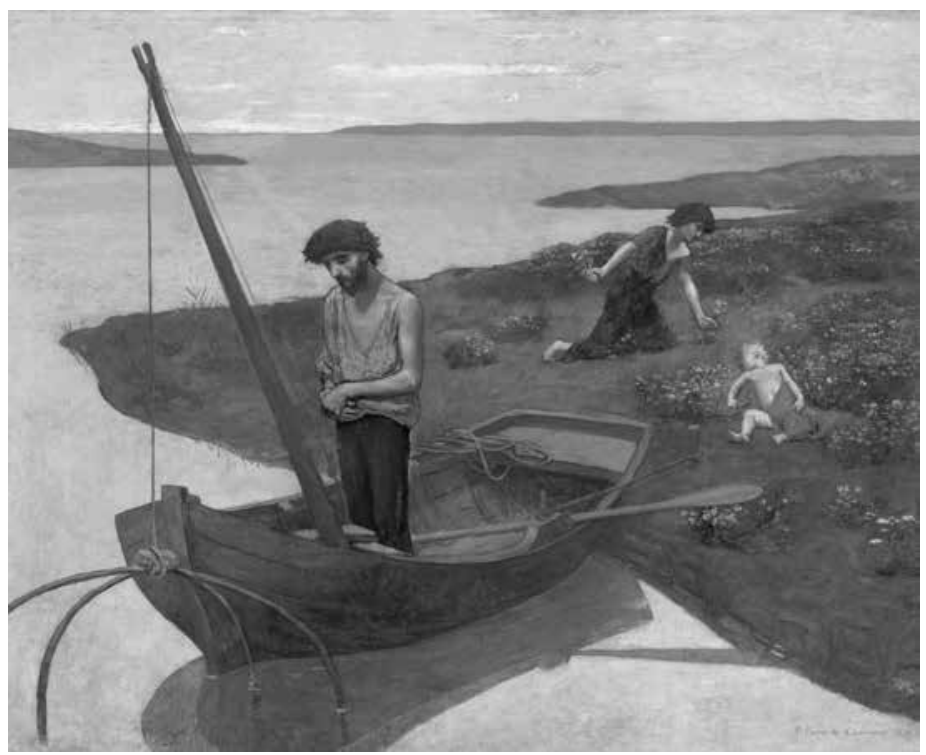

Pierre Puvis de Chavannes. Le Pauvre Pêcheur, 1881.

Óleo sobre tela, $155,5 \times 192,5 \mathrm{~cm}$. Paris, Museé d'Orsay

o mais notável pintor da III República: à maestria do desenho ele acrescentava ainda a utilização de uma paleta cromaticamente rica, que incorporava a luminosidade e o efeito atmosférico concebido pelos impressionistas. Além disso, recuperara um gênero havia muito em desuso - o muralismo - , que se adaptava perfeitamente às demandas políticas do momento: o governo francês compreendia as pinturas como discursos visuais com funções claramente pedagógicas, destinadas à educação das massas, e, nesse sentido, a pintura mural era a saída perfeita. Com isso, Puvis de Chavannes se tornou uma espécie de pintor oficial do regime, recebendo diversas encomendas de grande vulto, como as incumbências de decorar o Panthéon, as paredes da Sorbonne e as do Hôtel de Ville.

Esteticamente, Puvis de Chavannes obtinha combinações visuais que agradavam a muitos. Por um lado, aos partidários da tradição acadêmica, por executar pinturas cujo teor, caráter e tamanho se adequavam ao gênero histórico; por outro, também a elite política da época se encantava com a renovação das figurações por ele criadas. Sua interpretação de Sainte Geneviève como uma mártir de origem popular, cujo patriotismo era sincero e comovente, sem ser necessariamente bélico, era com muita probabilidade a encarnação mais perfeita das virtudes a que o novo regime aspirava. E, por fim, seu cromatismo vivo 
e suave demonstrava um diálogo com as vanguardas, contribuindo para que fosse elevado à condição de pintor oficial, sem ser visto como um "passadista”, ou seja, mais um típico artista pompier dedicado a acrescentar inovações, muitas vezes artificiais e anedóticas, ao grande gênero. ${ }^{13} \mathrm{O}$ fato de Belmiro ter procurado inspiração em um artista como Puvis de Chavannes é algo importante para que pensemos o que tal geração de artistas entendia por "arte moderna". Tratava-se de escolher como modelo um pintor que era visto como a síntese perfeita entre duas escolas antípodas (a acadêmica e a impressionista) e que, ademais, havia consolidado a representação iconográfica emblemática do regime republicano.

Também Belmiro parecia procurar demonstrar o quanto dominava duas escolas, pois de um lado realizava uma obra de caráter histórico, com o que evidenciava seu diálogo com a tradição acadêmica. Mas, ao mesmo tempo esboçava elementos então identificados como inovadores, entre eles, essa paisagem diáfana que incorporava elementos estéticos simbolistas, distanciando-o de uma escola naturalista de pintura, e a moldura art nouveau que até hoje é utilizada pela tela, a qual é uma marca inegável de modernidade. Mas o aspecto crucial é mesmo a representação iconográfica que estampa ${ }^{14}$.

$\mathrm{Na}$ tela estão figurados dois homens perdidos em meio a uma natureza exuberante e selvagem. Trata-se de dois desterrados que desembarcaram em terras novas, desconhecidas até então pela civilização europeia. Esse momento nada tem de glorioso. É desse abandono original, que leva as figuras masculinas - aliás pouco heroicas - ao desespero e ao desalento, que nasce o nosso país, o Brasil. Nesse pessimismo subjacente à tela podese perceber um diálogo, mordaz, com a tradição da pintura de história local. Belmiro se recusou a representar o descobrimento como um ato fundador digno de celebração, recusou-se também a enaltecer a natureza tropical, como tantos artistas imperiais haviam feito antes dele. O pintor representou o "marco inaugural" da nação como um momento de abandono, involuntário, de dois homens fragilizados, desprotegidos diante de uma natureza assustadora. E ao fazê-lo traduziu um espírito crítico com relação à tradição artística anterior. Talvez para Belmiro, o lema do artista moderno estivesse aí resumido: ele deveria procurar romper com a perspectiva idealista e oficial da arte produzida durante o Império, por meio de temas novos, ou interpretações mais críticas e independentes.

13. Cf. vaisse, Pierre. La Troisième République et les peintres. Paris: Flammarion, 1995.

14. Agradecemos ao professor Luciano Migliaccio pela sugestão de interpretação do caráter inovador da moldura na referida obra. 


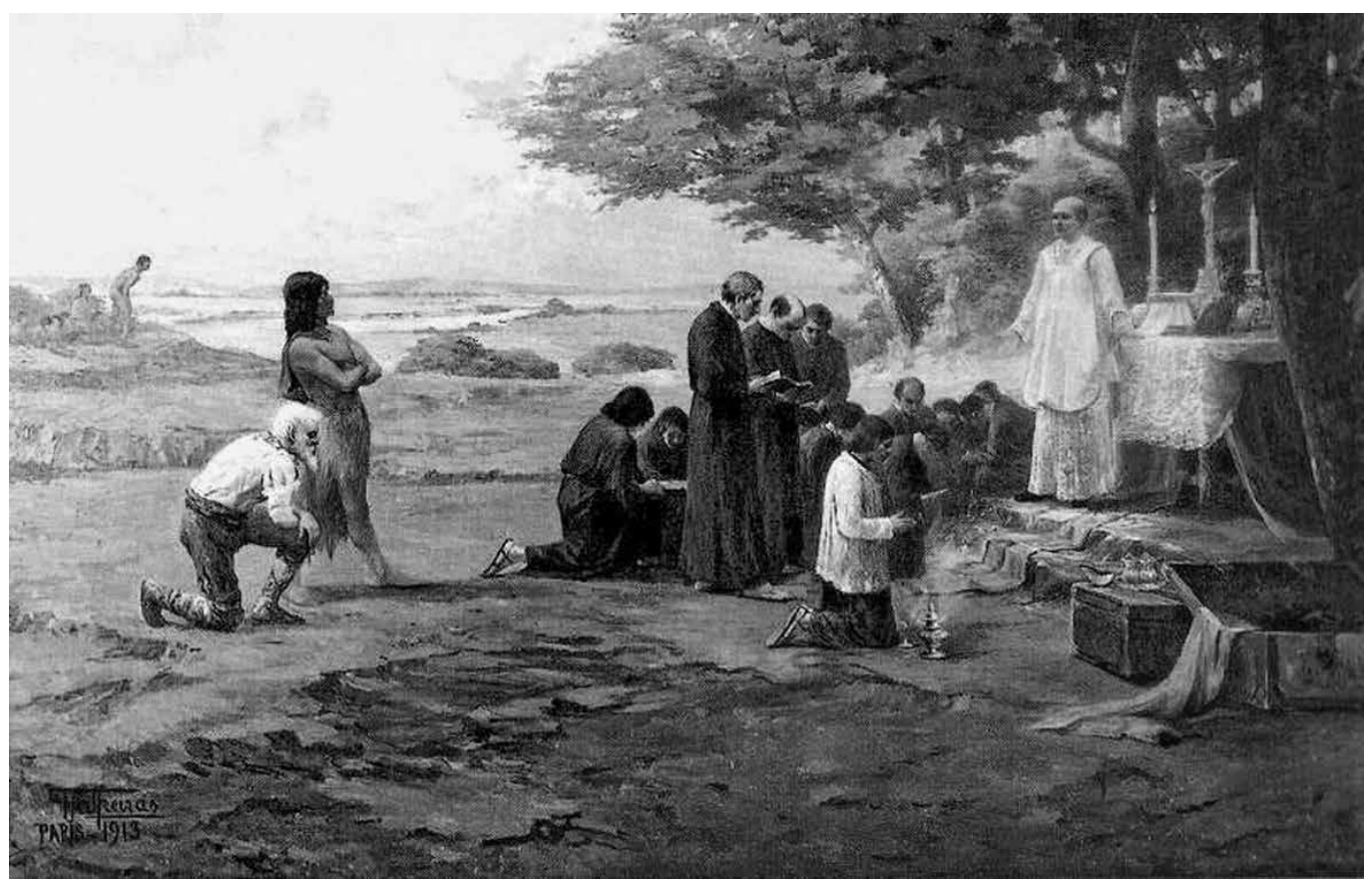

Antônio Parreiras. Fundação da cidade de São Paulo, 1913.

São Paulo, Pinacoteca Municipal de São Paulo, 200 × $300 \mathrm{~cm}$.

Opção semelhante pode ser analisada na obra de Antônio Parreiras (1860-1937), artista fluminense que, apesar de ter-se consagrado como paisagista oriundo da escola de George Grimm, ${ }^{15}$ possui uma obra bastante diversificada, na qual se exercitou em vários gêneros tradicionalmente valorizados pelo campo acadêmico, como os nus, as paisagens e, notadamente, as obras de cunho histórico sobretudo a partir da proclamação da República. A partir de 1905, num intervalo de tempo que iria até os idos da década de 1920, o artista fluminense se torna um dos mais requisitados pintores de telas históricas da República, executando cerca de trinta obras de cunho histórico para os mais variados

15. O chamado "Grupo Grimm" fora também composto por pintores como Thomas Driendl, Domingo Vasquez, Hipólito Caron, Giambattista Castagneto, França Junior e Francisco Ribeiro. Sobre isso ver: LEvy, Carlos Roberto Maciel. O Grupo Grimm. Rio de Janeiro: Pinakotheke, 1980. 
governos locais, como já referimos acima. Nesse período, Parreiras mantém ateliês em Niterói e em Paris, cruzando o Atlântico a cada dois anos, em média. Geralmente os retornos à terra natal são ditados pelas exigências de entregas de encomendas e obtenção de novos contratos que lhe financiem novas temporadas no exterior.

Ao analisar o conjunto da obra referente aos quadros de cunho histórico de Parreiras, nota-se a recorrência de temas demarcados cronologicamente. Em uma primeira fase, executada entre os anos de 1901 e 1913, o pintor encena majoritariamente atos de fundações e descobrimento. Entre os anos de 1914 e 1928, cria telas que representam em sua maioria heróis regionais e revoltas populares. Importante destacar que este tipo de tema, abolido do repertório imagético durante a vigência do regime imperial, emerge com força no nascimento da República, momento em que os estados federativos recém-constituídos buscavam afirmar seu quinhão na história da nação. Os últimos quadros históricos pintados por Parreiras entre os anos de 1928 e 1936 retomam o tema do bandeirantismo ora de forma crítica, ora heroica. ${ }^{16}$

Parreiras inicia a produção de quadros históricos em um momento de sua trajetória em que já era um paisagista renomado e aclamado pela crítica de arte. O pintor estava, porém, passando por um período de alheamento no campo artístico, fruto das tensões que se seguiram às reformas realizadas na Escola Nacional de Belas Artes.

O pintor fluminense, ao capitanear publicamente a reação às mudanças realizadas na ENBA, ${ }^{17}$ acaba excluído do establishment artístico organizado em torno da instituição de ensino. Parreiras fora demitido da Escola em 1891, quando a reforma curricular extingue a cadeira de paisagem, por ele lecionada. Nesta ocasião, o pintor se enfileira a Pedro Américo e Victor Meirelles, afastados por sua intrínseca identificação com o antigo regime imperial..$^{18}$

16. Referimo-nos respectivamente aos seguintes quadros: 1901-1913: A chegada, 1900; A partida, 1901; Conquistado Amazonas, 1907; Fundação de Niterói, 1909; Morte de Estácio de Sá, 1911; Fundação de São Paulo e Instituição da Câmara Municipal, 1913; 1914-1928: Proclamação da República Piratini, Retrato de Bento Gonçalves e Prisão de Tiradentes, 1914; Frei Miguelinho, 1917; José Pelegrino, 1917; Morte de Paes Leme, 1920; Anchieta, 1921; Felipe dos Santos, 1922; Zumbi dos Palmares, 1927; Juan Hernandez, 1927; Frei Caneca, 1928; 1928-1936: As esmeraldas, 1928; Eldorado, 1928; Os invasores, 1936.

17. Entre os anos de 1890 e 1891, Antônio Parreiras assinaria dezenas de artigos nos jornais cariocas polemizando com a direção da Escola Nacional de Belas Artes por questionar os rumos da reforma que fora implementada tendo à frente Rodolfo Bernardelli e Rodolfo Amoedo.

18. STUMPF, Lúcia K. A terceira margem do rio: mercado e sujeitos na pintura de história de Antônio Parreiras. 
Com o falecimento de Victor Meirelles em 1903, e o de Pedro Américo apenas dois anos depois, Parreiras possivelmente desejou assumir o legado desses, que foram reconhecidos como os grandes mestres da pintura de história do Brasil. Para celebrar o novo regime republicano a partir das encomendas regionais que recebe, o pintor fluminense não poupara citações à obra dos dois pintores que melhor se valeram de seus pincéis para louvar os feitos do Império brasileiro.Uma retomada da tradição oitocentista, facilmente identificada nas telas históricas de Parreiras, ocorre, porém, não de forma descontextualizada. Ao mesmo tempo que retoma temas e faz citações dos grandes expoentes da pintura do Império, o artista opera mudanças que deixam entrever uma tensão entre sua produção e a tradição. Para melhor compreensão do que estamos tentando demonstrar, analisaremos o quadro Fundação da cidade de São Paulo, realizado em Paris por encomenda da Prefeitura de São Paulo e concluído em 1913.

Desde 1893, ano em que realiza a primeira exposição individual na capital paulista, Antônio Parreiras estabelece uma profícua relação com as elites econômicas locais. $\mathrm{Na}$ cidade, que via sua economia e importância política crescerem rapidamente após a República, o pintor obtém encomendas de pintura de retratos de propriedades por famílias influentes como as de Júlio de Mesquita e Viridiana Prado. ${ }^{19}$

Anos mais tarde, em 1913, Parreiras recebe de Raymundo Duprat, então prefeito de São Paulo, a encomenda para a execução de dois quadros históricos: Fundação da cidade de São Paulo e Instituição da Câmara Municipal de São Paulo, que seriam destinados à decoração das sedes da Prefeitura e da Câmara de Vereadores, respectivamente. Pela entrega dos dois quadros o pintor receberia a quantia de vinte contos de réis. ${ }^{20}$

$\mathrm{O}$ artista realiza um detalhado estudo documental para a composição da cena que deveria representar o ato de fundação da cidade de São Paulo, ocorrida em 25 de janeiro de 1554 nos campos de Piratininga através de uma missa campal rezada pelo Padre Manoel de Paiva. Segundo anotações do próprio pintor:

A missa foi rezada sobre a colina onde hoje está o Palácio do Governo e existiu a primitiva igreja erguida onde estava o colégio. Estavam presentes os seguintes missionários:

Dissertação de mestrado apresentada ao Instituto de Estudos Brasileiros da Universidade de São Paulo, 2014. 19. LEVy, C. R. M. AntônioParreiras: pintor de paisagens, gênero e história. Rio de Janeiro: Pinakotheke, 1981, p. 38-9.

20. Cf. Documento IP 50361-4 do Arquivo do Museu Antônio Parreiras, Niterói, RJ. 
Anchieta, Gregório Serrão, Diogo Jacome, Leonardo Nunes, Gaspar Lourenço, Vicente Rodrigues, Brás Lourenço, Pedro Correia, Manoel Chaves, João Gonçalves e Antonio Blasque além dos índios Tibiriçá e Camby.

A paisagem representa a colina, em cujo alto se armou o altar, junto a um grupo de árvores. À esquerda do observador, os campos e o rio Tamanduatey. ${ }^{21}$

Ao olhar para o quadro, que ainda hoje pertence ao acervo da Prefeitura de São Paulo, vemos uma cena que nos remete à tradição de representação da celebração das primeiras missas. A ação principal desenrola-se na metade direita do quadro, onde estão localizados o altar e o padre, que se volta a uma audiência formada por clérigos que acompanham a liturgia da celebração. Na outra metade do quadro, livre de vegetação, dois grupos são representados em destaque. O primeiro, retratado no mesmo plano da cena da missa, é composto por um homem branco, que, afastado do grupo de clérigos, se mantém ajoelhado em posição de respeito à liturgia, e por um índio que está junto dele, mas de pé, em postura altiva e de braços cruzados. Mais ao fundo, conformando e quase se confundindo com a paisagem, vê-se um grupo de índios algo receoso com o que se passa na cena em destaque.

A representação do ato de fundação territorial no momento de realização de um culto religioso faz parte do repertório brasileiro desde o célebre quadro de Victor Meirelles, A primeira missa no Brasil, pintado em 1860, e remonta a uma tradição ainda mais longeva. ${ }^{22}$ Pedro Peres foi o primeiro a retomá-la ao pintar A elevação da cruz, em 1879. O próprio Parreiras já havia feito em 1907 uma citação ainda mais literal à tela do pintor catarinense, quando cria o quadro Conquista do Amazonas, por encomenda do governo do Pará.

A opção de Parreiras por representar a fundação da cidade de São Paulo a partir do ato ecumênico é uma demarcação por uma retomada da tradição oitocentista. Não

21. SAlgueiro, Valeria. Antônio Parreiras: notas e críticas, discursos e contos. Rio de Janeiro: Eduff, 200o, p. 94.

22. Sobre isso ler: ColI, Jorge. "A invenção da descoberta". In: Como estudar a arte brasileira do século Xx?. São Paulo: Editora SENAC, 2005. 


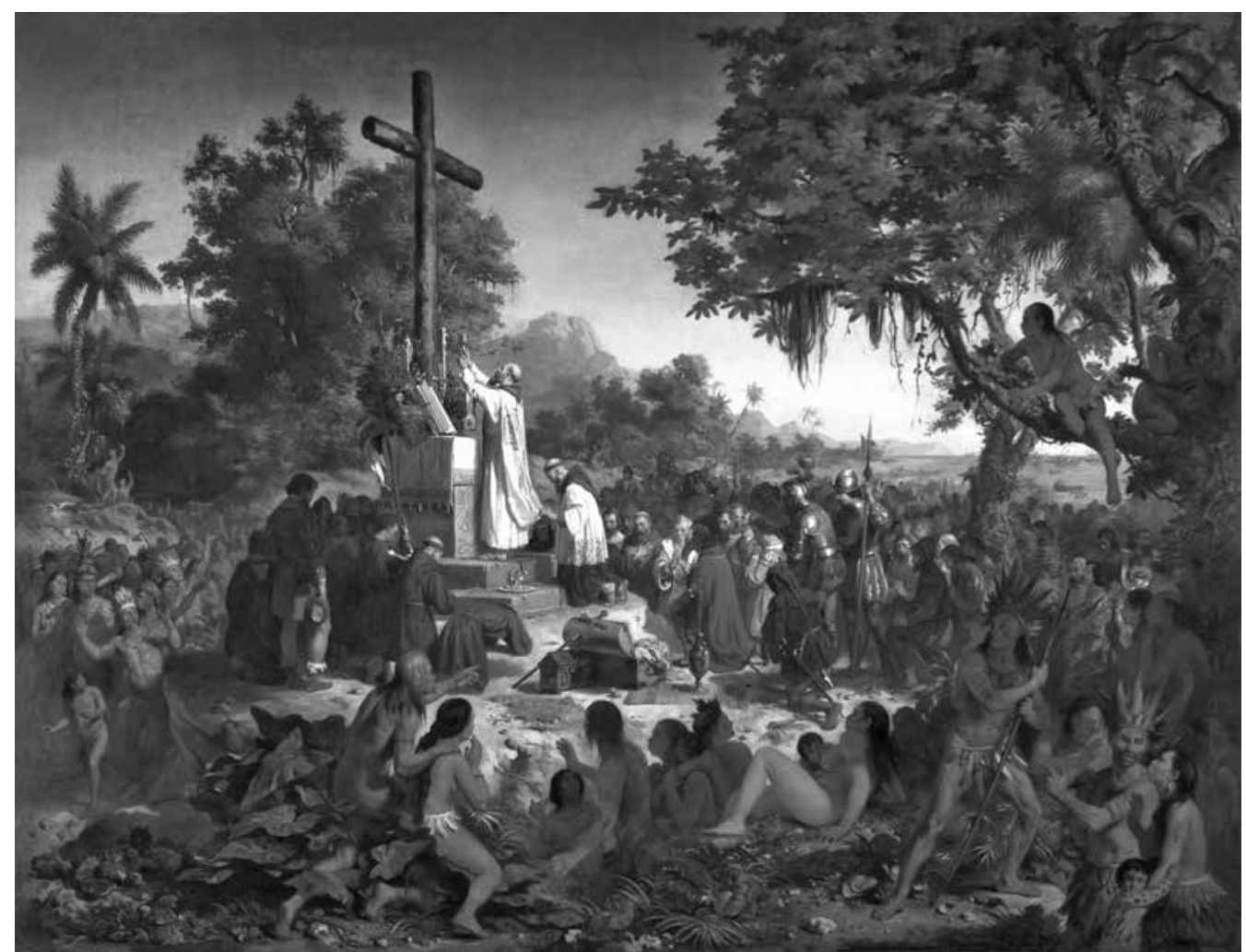

Victor Meirelles. Primeira missa no Brasil, 1860.

Óleo sobre tela, $268 \times 356 \mathrm{~cm}$. Rio de Janeiro, Museu Nacional de Belas Artes.

só na escolha do tema, mas também na representação da cena principal retratada, a realização da missa, o artista fluminense bebe da fonte dos pintores acadêmicos. O grupo de clérigos que acompanha a missa parece retirado do quadro de Meirelles. O altar apresenta grande semelhança. Na tela de Parreiras, porém, a grande cruz que marca a composição de Meirelles é substituída pela vegetação que se impõe sobre todo o grupo.

Se, ao analisar o quadro de Parreiras, nos concentrássemos apenas no grupo em torno do qual se desenrola a cena principal, veríamos pouco além da perpetuação de um modelo passadista em pleno século xx. Porém, o personagem central do quadro de Parreiras não é o padre que reza a missa, nem o altar sobre o qual ela acontece, tampouco o grupo de jesuítas ao redor. 
O elemento que primeiro chama a atenção do observador da tela é o índio que assiste a tudo impávido. $\mathrm{O}$ pintor deliberadamente colocou o índio em uma posição livre de vegetação ou de outros elementos que disputem a atenção do olhar. Como forma de ressaltar sua postura altiva, Parreiras acrescenta um homem branco civil à cena que, ao aparecer ajoelhado bem ao lado do índio, gera com ele um contraste de cores e volumes.

A afirmação de que o homem branco que aparece ajoelhado está em cena para destacar ainda mais a postura do índio deriva da observação das anotações do pintor. No trecho reproduzido acima, em que ele nomina os indivíduos retratados no quadro, podemos notar que não há qualquer referência a este personagem —são citados apenas os jesuítas e os índios. Além disso, outro trecho de suas anotações, que aparece sublinhado em vermelho, confirma essa percepção:

Alguns historiadores dizem que João Ramalho assistiu à Fundação de São Paulo. Não é verdade. Ramalho estava em Santo André. ${ }^{23}$

Faz-se importante neste momento notar que este homem retratado no quadro se assemelha muito à representação que o pintor fará de João Ramalho na tela encomendada no mesmo ato da Fundação de São Paulo, Instituição da Câmara Municipal. Além de servir ao fim estético de contrastar com o indígena em cena, o retrato de João Ramalho responde a uma demanda política do período. Dentro do IHGSP travou-se um debate sobre quem devia ser consagrado como o progenitor dos paulistas. Duas correntes disputavam a versão. A saber, a dos jesuítas e a dos que pretendiam reabilitar João Ramalho, figura polêmica na historiografia local. Ao realizar uma tela sob encomenda da Prefeitura de São Paulo poucos anos depois de Oscar Pereira da Silva ter retratado a mesma cena sem dar destaque à presença do bandeirante, Parreiras demonstra estar respondendo a um pedido do encomendante. ${ }^{24}$

O índio colocado desta forma e com este destaque no quadro garante à cena de fundação uma leitura crítica. Os braços cruzados do índio contrastam com as mãos espalmadas do padre que reza a missa. O corpo levemente jogado para trás com a cabe-

23. SAlgueiro, Valeria, op. cit., p. 94.

24. Cf. monteiro, Michelli Cristine Scapol. Fundação de São Paulo, de Oscar Pereira da Silva: trajetórias de uma imagem urbana. Dissertação de mestrado. FAU/USP, 2012. 
ça erguida se contrapõe ao gestual de todos os demais espectadores que se prostram frente ao altar.

Desta forma, a partir da inserção de um elemento que ganha ares de ironia, o quadro executado para eternizar o gesto fundador da cidade de São Paulo acaba por questioná -lo, caracterizando uma ruptura com a tradição iconográfica. Ao utilizar-se de elementos que ora dialogam com a tradição ora apontam para uma ruptura com ela, Parreiras parece aproximar-se da mesma estratégia adotada por Belmiro de Almeida, a saber, a de provocar uma retomada crítica da tradição artística em que se formaram. Ambas as telas retomam o modelo de fundação da nação elaborado por Victor Meirelles, em um caso figurando a chegada dos portugueses às novas terras, e em outro, o momento de início da civilização por meio da cristianização dos bárbaros nativos. Em ambos os casos, porém, as distâncias são evidentes. Parreiras rompe com a docilidade e a passividade dos indígenas retratados por Meirelles ao representar um homem indígena em pé, de braços cruzados e olhar desconfiado, o que não deixa de ser também uma contraposição à Moema morta sobre as areias do mar, outra célebre tela do pintor catarinense.

Os Descobridores retoma o tema da descoberta, mas se em Meirelles a natureza seduzia e coroava um suposto paraíso tropical, agora ela se apresenta como desterro. Diferindo da ideia de um encontro pacífico e suave entre nações, abraçado por uma natureza majestosa, subjaz aqui uma ironia profunda: que tipo de civilização pode se originar do encontro entre dois homens? Não há possibilidade de reprodução, de filhos que mitifiquem uma nova nação. Aqui, representa-se, ao fim e ao cabo, a impossibilidade de um novo devir, não há frutos possíveis desse encontro inesperado, o que implica a negação de muitos dos mitos de origem criados e cultuados pela cultura artística do Segundo Reinado ${ }^{25}$.

Conforme o próprio José Murilo de Carvalho demonstra em seu livro, a República não foi capaz de arrebatar o povo e, no mesmo sentido, de polarizar a adesão de intelectuais e artistas. Pelo contrário, as críticas e decepções com os limites do novo regime deram a tônica. Daí o erro do autor em considerar a inexistência de uma estética própria - a estética própria da República foi formada, inclusive, por este ceticismo, por esta ironia, diante de um novo regime que foi, em muitos casos, decepcionante. Esta ironia cética muitas vezes se projetava em direção ao passado, não permitindo que os

25. A esse respeito ver também, Migliaccio, Luciano. "Arte do século xix". In: Mostra do Redescobrimento. Arte Brasileira do Século XIX. São Paulo: Fundação Bienal de São Paulo, 2000.

128 • SIMIONI, Ana Paula C. \& STUMPF, Lúcia. O Moderno antes do Modernismo... 
artistas realizassem mitificações completas, ou que eles ao menos, ao "inventarem" estes heróis, o fizessem deixando ruídos, verdadeiros marcadores deste tipo de insatisfação. Note-se que para descrever os sentidos evocados pelas duas telas utilizamos uma mesma palavra, "ironia". Talvez esteja justamente aí a chave para que se entenda o sentido que os artistas contemporâneos à implantação da República desejavam atribuir à modernidade de suas produções. Trata-se, certamente, de um sentido de Moderno anterior e distinto daquele empregado, décadas mais tarde, pelos chamados modernistas. Entender o Moderno antes do Modernismo passa por dedicarmo-nos a um olhar atento, livre dos juízos estéticos anacrônicos a que fomos submetidos com a supremacia do legado modernista na cultura brasileira. Só assim poderemos ver que a República gerou sim uma estética própria, e entender seu significado preciso, historicamente produzido.

Ana Paula Cavalcanti Simioni é docente no Instituto de Estudos Brasileiros da USP. Autora do livro Profissão artista: pintoras e escultoras acadêmicas brasileiras (Edusp, 2008).

Lúcia K. Stumpf é mestre em Culturas e Identidades Brasileiras, pelo Instituto de Estudos Brasileiros da USP e doutoranda do Programa de Pós-Graduação em Antropologia Social da USP. 